\title{
FORMAÇÃO E COMPETÊNCIAS EM SILVIO ROMERO: UMA LEITURA
}

\author{
TRAINING AND SKILLS IN SILVIO ROMERO: ONE READ
}

\begin{abstract}
A enumeração ou classificação dos problemas sociais deve partir dos fatos mais íntimos e indispensáveis à vida, sem os quais nem a própria subsistência da gente a estudar seria possível.( Silvio Romero, 1906).
\end{abstract}

Carlos Alberto Vasconcelos ${ }^{3}$

\begin{abstract}
Resumo
O presente texto aborda considerações sobre o ilustre Silvio Romero, suas leituras pedagógicas, formação e competências. Apoia-se especificamente em trabalhos monográficos realizados pelos alunos do curso de Pedagogia e do Mestrado em Educação da Universidade Federal de Sergipe, com o sentido de resgatar a memória desse sergipano que em muito contribuiu para os estudos educacionais no país. Descreve sucintamente sobre origem, ideologia e pensamento pedagógico dentro de uma sociedade moderna, principalmente no século XIX. Foi escrito com base em pesquisas bibliográficas, tomando-se como referencial autores classicos: Roger Chartier, Raul Pompeia e autores contemporâneos, a exemplo de Souza (2006), Araújo (2004) e Nascimento (1997 e 2007), além de fontes históricas do arquivo da Biblioteca Epifânio Dória e da Universidade Federal de Sergipe.
\end{abstract}

Palavras-chave: Leitura educacional. Sílvio Romero. Formação e competência.

\begin{abstract}
This text deals with considerations on the illustrious Silvio Romero's readings, education and competences. It is based on monographic work carried out by students of the Pedagogy and the Masters in Education courses of the Universidade Federal de Sergipe- Federal University of Sergipe, with the aim of recalling the memory of this scholar, born in the state of SergipeBrazil, who contributed to the educational studies in the whole country. It briefly describes the origins, ideology and pedagogical thinking within a modern society, especially in the 19th century. It was written on the basis of bibliographic research, taking as reference classical authors such as Roger Chartier, Raul Pompeia and contemporary authors like Souza (2006), Araújo (2004) and Nascimento (1997 and 2007), as well as historical sources gathered from the Biblioteca Epifânio Dória - Epifânio Dória Library - and the Universidade Federal de Sergipe.
\end{abstract}

Key-words: Reading education. Sílvio Romero. Education and competence.

\footnotetext{
3 Mestrado (2000), Doutorado (2009) em Geografia pela Universidade Federal de Sergipe e Estágio Pós Doutoral em Educação Contemporânea (UFPE). Professor Adjunto do Depto de Educação do Campus Prof. Alberto Carvalho e do Programa de Pós-graduação em Ensino de Ciências Naturais e Matemática (PPGECIMA) na UFS. E-mail : geopedagogia@yahoo.com.br
} 


\section{Introdução}

Escrever sobre os intelectuais da educação é, antes de tudo, resgatar a história e reafirmar a condição do indivíduo como sujeito, colocando em evidência as personalidades, no processo de vida social.

Fazer uma análise histórica da gênese e das competências pedagógicas de Silvio Romero requer entre outros, estudos, de psicologia e da sociologia. Sílvio seguia este campo até o limite das possibilidades da visão política, ao considerar legítimo o direito de subelevação das massas. Considerado como um intelectual importante durante a segunda metade do século XIX, o ilustre Silvio Romero viu chegar o século XX aos 50 anos de idade com reconhecimento de ser o maior crítico literário brasileiro.

Com esse entendimento, o corrente texto apresenta como propósito principal discorrer sobre a História da Educação a partir da formação e competências de Silvio Romero. Originou-se a partir de leituras direcionadas à temática em trabalhos acadêmicos desenvolvidos por alunos da graduação na disciplina Filosofia da Educação, da Faculdade Pio Décimo, em Aracaju, estado de Sergipe, e do conteúdo programático da disciplina "Literatura como fonte para o estudo da História da Educação", ofertada pelo Mestrado em Educação da Universidade Federal de Sergipe. As leituras e as investigações foram desenvolvidas principalmente na Biblioteca Pública Epifanio Dórea e na biblioteca central da Universidade Federal de Sergipe, as quais possibilitaram a aproximação e uma compreensão melhor do objeto de estudo.

O despertar por essa temática foi impulsionado por uma questão pessoal como também por querer tratar e conhecer melhor os intelectuais sergipanos que contribuíram para a formação intelectual do país. Buscaram-se subsídios para elucidar as questões referentes ao citado tema levantamentos bibliográficos especificamente oriundos de espaços universitários, a exemplo de revistas, artigos, livros e monografias (TCC, dissertações e teses), que, de maneira sistemática, contribuíram para a análise dos diversos questionamentos sobre a educação brasileira e para a sustentação teórica. Dentre os autores consultados, podemos mencionar Roger Chartier (2002), Raul Pompéia (1971), Carlo Ginzburg (1989), Jorge C. Nascimento (1997, 2007), J. A. M. Araújo (2004) e Cristiane V. de Souza (2006), para tentar compreender o panorama do que fora o pensamento sobre a educação brasileira do século XIX.

Epistemologicamente, Sílvio Romero aderiu, em sua fase inicial ou fase de adesão, ao Positivismo e ao Materialismo de Vogt e Moleschott. Segundo interpretações de Paim (1966), 
tratava de um período propriamente pernambucano, já que viveu naquela província como estudante até o ano de 1873, ausentando-se por um breve tempo para em seguida retornar a fim de submeter-se a exames para ingresso no magistério. A produção desse período consiste inteiramente de artigos, predominando os de crítica literária.

Mais adiante chega a combater o ecletismo espiritualista e a metafisica, rompendo mais tarde com o Positivismo, o que tornou sua obra veementemente contestada por intelectuais positivistas da época. Como a maior parte dos intelectuais da escola do Recife, Sílvio Romero compôs o núcleo central da sua concepção de mundo a partir de leituras monistas e evolucionistas, principalmente a partir das interpretações que retirou de estudiosos como Wolf, Ernest Haeckel, Ludwig Noiré, Charles Darwin e Herbert Spencer. Foi com os monistas e evolucionistas que Romero aprendeu a criticar o Posistivismo e ao mesmo tempo assumiu a defesa das ideias materialistas, tomando uma posição anticlerical e de críticas ao catolicismo. Ao longo da segunda metade do século XIX buscou sempre tornar popular a ideia de filosofia como epistemologia, pois assumia a posição de que a teoria do conhecimento era o objeto próprio da filosofia. (NASCIMENTO, 2007).

É importante destacar que Sílvio Romero iniciou sua atuação jornalística, na imprensa pernambucana, quando estudava o segundo ano do curso de Direito, publicando a monografia "A Poesia Contemporanea e a sua intuição naturalista". Desde então mantinha a colaboração como ensaísta, crítico e poeta nos jornais que circulavam em Recife.

\section{REFERENCIAL TEÓRICO}

\subsection{Biografando Sílvio Romero}

Sílvio Vasconcelos da Silveira Ramos Romero nasceu no dia 21 de abril de 1851, na vila de Lagarto, em Sergipe. Era filho de André Ramos Romero, "português do norte", negociante abastado, e Maria da Silveira Vasconcelos Ramos Romero, descendente de uma próspera família também de origem portuguesa. Silvio foi entregue aos cuidados de Antônia, mucama que lhe transmitiu os primeiros conhecimentos. Essa senhora cristã, seguidora dos mandamentos divinos, responsável pela educação moral e religiosa das crianças e adolescentes da família, ensinara-lhe muitas histórias.

O século XIX brasileiro foi marcado pela importância crescente do impresso, pois no início dessa era houve uma ampliação da circulação de livros, devido ao surgimento da 
imprensa, da proliferação de livrarias e bibliotecas (ARAÚJO, 1985). No entanto, a tradição oral continuou sendo durante muito tempo a principal forma de transmissão da cultura. As lembranças de Sílvio ilustram bem a relevância da literatura oral que muitas vezes provoca mais prazer nos ouvintes do que a literatura escrita. Para exemplificação, a literatura oral retratava contos:

Era uma vez.., o coração batia-me comovido, um calor inflamava-me o rosto, abriam-se muito os olhos e eu via, via os caminhos de encantos, as árvores de folhas de ouro, grutas de esmeraldas, os dragões que bufavam chamas, as serpentes, os cisnes, que eram príncipes encantados, as princesas cativas de monstros, todas as coisas e figuras desses poemas da infância, primeiros alimentos da imaginação (Discurso de Recepção ao Acadêmico Osório Duque-Estrada - ABL, 1916).

A tradição oral retrata as imaginações, narrativas da experiência de um sujeito ou de um povo por meio da oralidade, que segundo Schmidt, (1995) envolvem uma dupla finalidade: uma função pragmática, de transmissão da experiência e da cultura; e uma função terapêutica, de elaboração da própria experiência. Ao contar uma história sobre a origem de seu grupo ou de sua cultura, um velho não apenas insere um jovem na cadeia de transmissão da herança desse grupo; ao mesmo tempo, ele também se volta para a própria experiência e a retoma, restabelecendo significados.

Souza (2006, p. 89) apoiada nas leituras de Romero (1977), dizia: "Nunca livro algum, por mais notável que fosse o seu autor e celebrada a sua fábula, conseguiu atrair-me como aquela velha o fazia como um imã nos seus recontos”. Silvio teve acesso à literatura escrita nas escolas dos mestres Bomfim e Badú. O mestre Bomfim era professor particular. Essa categoria de professor às vezes era preferida pelas famílias mais abastadas. As escolas particulares funcionavam na residência do mestre ou do aluno. Não há muitas informações acerca da experiência de Sílvio na escola do referido mestre. Há apenas o registro de que o professor costumava morder as orelhas dos alunos que não cumpriam com seus deveres. (ROMERO, 1960).

Para as escolas públicas de primeiras letras, os professores eram reconhecidos e nomeados pelos órgãos do estado; funcionavam geralmente em espaços improvisados. Essas escolas tinham a mobília não uniforme; mesas e bancos apresentavam singularidade como: cartas de sílabas, compêndio de gramática, aritmética e doutrina cristã. Os métodos do ensino aplicados eram mútuos e simultâneos. Fazia-se uso dos castigos corporais para garantir a disciplina. A palmatória era bem conhecida.

Discutindo a temática, Ferro (2000, p. 173) ressalta: 
O medo do professor era tamanho que, quando as crianças brincavam no terreiro e percebiam ao longe a sua aproximação, paravam tudo, fugiam e se escondiam, para a maioria. O professor devia ser autoritário e repressor, era alguém investido de uma autoridade inquestionável e quase absoluta.

Sobre sua experiência na escola do professor Badu, Sílvio deixou comentários sobre os materiais didáticos utilizados, mas afirma que aprendera a ler. Eis relato deste ilustre, quando diz que

[...] aprendia-se a ler, em velhos autos, velhas sentenças fornecidas pelos cartórios dos escrivães forenses. Histórias detestáveis e enfadonhas eram sua impertinente banalidade. Eram-nos ministradas nesses poeirentos cartapácios, as sentenças manuscritas eram secundadas por impressos vulgares, incolores, próprios para ajudarem a ler; era um ler por ler sem incentivo, sem préstimo, sem estímulo nenhum. (ROMERO, 1906, p. 161).

Era normal o uso dos paleógrafos, livros escolares destinados ao aprendizado da leitura da letra manuscrita na instrução elementar. Todavia, Sílvio Romero estudou as primeiras letras usando o ensaio do método de leitura repentina, elaborado por Antônio Feliciano Castilho. Esse método prometia ensinar a ler e escrever em poucas lições e era indicado tanto para o uso das escolas quanto para o ambiente doméstico. (SOUZA, 2006).

Segundo interpretação da autora, nos últimos tempos da escola primária, Sílvio sofreu influencias de dois livros que foram base do ensinamento pelos mestres das primeiras letras: o primeiro, Epítome da história, de J. P. Xavier Pinheiro, por causa da descrição de nossa terra de Rocha Pita; e o segundo, Os Lusíadas, por muitos trechos que o encantavam. O Brasil da descrição de Pita ficou sendo o Brasil de fantasias e sentimentos. A poesia de Camões ainda hoje é uma das mais elevadas manifestações da arte no ver e sentir. Acrescenta-se em relação a primeira obra que ao lado das estórias contadas pelas escravas ela pode ter despertado seu nacionalismo, já que cultivava amor a pátria e a moral cristã.

A aplicação dos castigos e os "bolos" recebidos pelo menino Sílvio Romero também são referências constantes nas memórias e romances. Esse hábito é constante. Mesmo com a proibição de castigos físicos por uma lei de 1858, as autoridades provincianas continuavam tolerando o uso dos castigos corporais moderados. Essa forma de aprendizagem nem sempre dava prazer. Muitas vezes a leitura mais agradável era realizada longe dos olhos dos professores e dos familiares. Sílvio mostrava encantamento pela educação e por livros desde sua infância. Quando morava na vila, costumava participar das festas populares como reisados, cheganças, pastorais, taieiras, bumba-meu-boi e outras, encantando-se. 
Apesar de ter frequentado aulas em sua vila de origem, foi no Ateneu Fluminense que, aos 12 anos de idade, deu início aos estudos preparatórios visando ingressar na faculdade. No Ateneu, colégio da capital do país (na época), foi matriculado pelo pai em regime de internato. O colégio era instalado em um enorme casarão, com aparência de caserna, hospício, quartel; imagem que provocou um choque de ruptura com a vida familiar e o ingresso no internato. Deixava-se o lar, o convívio com os familiares e amigos para enfrentar um ambiente 'disciplinado' do colégio interno, que era um lugar de instrução e formação moral.

Tal fato é mencionado em descrição de Raul Pompéia (1971, p. 49) quando diz:

\begin{abstract}
O colégio era literalmente o mundo, um mundo em miniatura, ali estavam todas as pessoas, as paixões, o poder absoluto, a ambição do diretor. O ateneu é um colégio moralizado, eu aviso, muito a tempo [...], eu tenho um código, todas as culpas são prevenidas, uma pena para cada hipótese.
\end{abstract}

No século XIX, o ensino secundário tinha a função de habilitar os alunos para o ingresso nos cursos superiores. A escolha do currículo e dos compêndios empregados no colégio visava cumprir esse fim. Sílvio estudou latim, filosofia, retórica, poética, história e gramática. Além dessas disciplinas, eram exigidas as específicas para o curso de Direito: Francês, Inglês, Aritmética e Geometria. Sílvio aprendeu francês, inglês, espanhol e italiano; ele também afirmava que aprendeu a ler em Alemão.

Após o término do secundário, Sílvio apresentou-se perante a banca examinadora para os exames preparatórios, obtendo autorização para o ingresso no ensino superior. Aproveitou o capital econômico e social de sua família e escolheu o curso de Direito. Em 1868 seguiu para a capital de Pernambuco, com o intuito de estudar na influente Faculdade de Direito de Recife. Após cinco anos de intensa vida intelectual nessa cidade, Sílvio diplomou-se em 1873 e seguiu para a sua terra natal. Em 1878 assumiu a promotoria pública de Estância, na Província de Sergipe. No ano seguinte voltou para Recife a fim de apresentar sua tese de doutoramento, e nesse mesmo ano prestou concurso para a cadeira de filosofia do Colégio das Artes. Foi aprovado, mas não foi nomeado. Após esse fato seguiu para o Rio de Janeiro onde atuou até o seu falecimento em 1914.

No entanto, apesar da distância, nunca perdeu contato com a cidade nordestina, publicou vários livros, trocava correspondências com amigos e periódicos da época. Lançando mão do capital cultural adquirido na prestigiada Faculdade e do capital social de sua família foi nomeado Juiz Municipal e de Órfãos de Parati em 1876. Exerceu a magistratura até 1879. Durante esse período dedicou -se à organização dos artigos publicados nos jornais de Recife a fim de enfeixá-los em livro. Em 1878 publicou "Contos do fim do século", pela tipografia 
fluminense, e a "Filosofia no Brasil", pela tipografia Deutsche Zeitung, de Carlos Von Koseritz.

O ingresso no magistério garantiu-lhe o prestígio que ainda não havia conseguido. Após sua entrada no colégio Pedro II, publicou "Introdução à História da Literatura Brasileira", em 1881; “O naturalismo em literatura", em 1882; "Contos populares do Brasil"; "Últimos arpejos e ensaio de crítica parlamentar", em 1883, "Programa de cadeira de filosofia do direito"; "Valentim Magalhães", em 1884, "Estudos de literatura contemporânea”, "História da literatura brasileira" e "A verdade sobre o caso de Sergipe", em 1895. Sílvio, embora não tivesse enfrentado dificuldades para publicar seus livros, manteve viva a relação com a imprensa. Fundou uma revista, "Lucros e Perdas", na qual escreveu alguns artigos, cerca de oito, e continuou escrevendo na Gazeta de Notícias, Diário de Noticias, Jornal do Comércio, etc. (SOUZA, 2006).

Sílvio adquiriu competência em literatura: lia nos espaços e horários oportunos; em motivos necessários. Em suas leituras silenciosas, estabelecia uma relação com o seu interior. A leitura silenciosa permite aos leitores adquirirem o domínio do código escrito e uma melhor compreensão, ou seja, uma leitura extensiva. Isso não quer dizer que ele não fizesse leitura intensiva, que não lesse ao acaso ou por fruição, apenas pelo prazer de expressar a sua aprovação. Sílvio teve uma educação formal e informal que o auxiliou a desenvolver determinadas competências e prática profissional. Na vila de Lagarto, teve os primeiros contatos com o mundo do desconhecido. Aprendeu a ler nos manuscritos e "impressos incolores" das escolas de primeiras letras dos professores Bomfim e Badu. Em Recife, adquiriu conhecimentos filosóficos e científicos nas aulas dos mestres, através de múltiplas leituras que realizou. Na capital federal (na época, Rio de Janeiro) deu continuidade a sua formação. Como autodidata, lia em casa, no bonde, na barca, na livraria, no escritório; lia silenciosa e extensivamente e escreveu intensamente.

Com isso, podemos observar que as competências e práticas que ele desenvolveu tornaram-no crítico das leituras nacionais e estrangeiras. Seus estudos ajudaram-no a reforçar seu interesse pelas coisas da terra e o introduziram no germanismo.

A partir das leituras das obras de Chartier, especificamente de "À beira da falésia", de 2002, deduz-se que a proliferação de livros ocasionada pela segunda Revolução Industrial, como do avanço da imprensa, fez com que as bibliotecas superassem a sua capacidade de conservação, levando-as a fazer a triagem do que podia ser preservado. 
Romero tinha, nesse sentido, o sonho de uma biblioteca universal onde todos os textos produzidos estivessem reunidos e onde fossem encontrados vestígios materiais, como carimbos, selos e inscrições em alto relevo achados nos livros que lhe pertenciam, os quais eram comprados em brochuras, encadernação simples, e Sílvio ganhava diversos livros, inclusive de autores amigos.

\subsection{A construção do pensamento pedagógico}

É importante compreender como Sílvio Romero apropriou-se das leituras e escreveu sobre a educação, o que demonstra a importância de ambas na construção do seu pensamento pedagógico. A educação adquiriu importância no pensamento Spenceriano, de experiências e esquemas de comportamento. Assim, a educação inculcou nos indivíduos comportamentos moralmente adequados à sociedade industrial.

Para implementação desta concepção como propósito de adaptação, poderiam ser introduzidas, a longo prazo, modificações essenciais na espécie, de modo a garantir a sobrevivência dos mais aptos e a evolução social, pois não podemos descartar que existe uma relaçao íntima e permanente entre o biológico e o sociológico.

Para tornar possível essa ideia de educação, era necessário renovar o currículo. Para Romero os conhecimentos de maior valor seriam os científicos, porque são os únicos capazes de fornecer ao indivíduo as condições necessárias à luta pela existência. Então, priorizou as disciplinas científicas em detrimento das clássicas. Entre as disciplinas que deveriam constar no currículo considerou significativas: lógica, matemática, geometria, biologia, psicologia, sociologia e história. Embora muitos julguem que ciência e religião são incompatíveis, Spence julgou-as conciliáveis e defendeu a mudança dos conteúdos, pois considera a criança uma tabula rasa, um mero receptor das ideias de outrem. Defendeu que os mestres deveriam transmitir o conhecimento científico partindo do simples para o complexo, do concreto para o abstrato, do empírico para o racional, respeitando a evolução psicológica dos alunos. Os mestres deveriam oferecer algumas noções científicas e deixarem o educando tirar suas próprias conclusões. Seguindo esse itinerário, o aprendizado seria compatível com as leis da natureza; espontâneo e agradável. Um homem educado desse modo ficaria preparado para instruir-se a si mesmo e por toda a vida.

Para Spencer (1894), a evolução social depende do aperfeiçoamento do caráter dos indivíduos que compõem o organismo social e não das reformas das instituições, como se costuma pensar. Para realizar a tarefa de preparar os filhos para a vida, a família, responsável 
por esse tipo de educação deve mostrar as consequências das boas e das más condutas para que eles possam conhecer a justiça das penalidades que serão aplicadas pela natureza, ao contrário de muitos pedagogos do século XIX que tendiam à aplicação dos castigos.

Esse autor chamou a atenção para o esquecimento por que vinha passando a educação física. Para ele, isso é inadmissível, pois a evolução depende do vigor físico dos seus indivíduos. Os excessos devem ser evitados, pois a educação é uma das principais conquistas das sociedades modernas e é imprescindível como "arma do aperfeiçoamento na luta pela existência".

Spencer mencionou que nas escolas públicas da Inglaterra, os conhecimentos científicos realmente úteis estão relacionados à posição de instrução suplementar. Esta questão foi debatida por Sílvio nos textos intitulados: "Notas sobre o ensino público" e "O Brasil na primeira década do século XX". Romero condenou a ênfase ao ensino prático, científico, ao tratar dos conteúdos a serem ministrados nas escolas primárias. Para ele haviam duas concepções distintas acerca da liberdade de ensino: a brasileira e a prussiana. A brasileira permitiria que qualquer pessoa pudesse ensinar desde que siga os programas formulados pelo governo. A concepção prussiana controla o acesso ao magistério, exigindo uma instrução sólida e garante a liberdade de métodos e doutrinas. Para esse intelectual, somente a União poderá imprimir um caráter nacional à educação. Cabia ao Estado a tarefa de controlar o ensino público, fornecer as diretrizes do ensino público secundário através de colégio modelo, fiscalizar as escolas particulares, organizar os concursos para habilitação de professores e delimitar as matérias a serem estudadas e fiscalizadas para os exames finais.

Em seguida, avaliou o regime escolar vigente na Alemanha, país também construído por povos de formação comunitária de Estado, e destacou que o objetivo do regime escolar alemão é preparar os indivíduos do ponto de vista técnico, oferecendo-lhes uma educação literária de qualidade. Para Demolins, os povos anglo-saxões têm maior possibilidade de alcançar a felicidade do que os franceses. Uma solução para isso seria tentar modificar as leis educacionais na França, adotando o modelo anglo-saxão de educar. Demolins (s.d) afirmou que os alemães pecam por defender uma educação militarizada voltada para a soberania nacional. Sílvio contestou, dizendo que a Alemanha tem formação comunitária de Estado e outras vezes faz exceção para a planície saxônica.

Demolins é reconhecido pela sua contribuição à pedagogia e é considerado um dos integrantes do movimento da escola nova, que, entre a última década do século XIX e a 
terceira década do século XX, afirmou-se na pedagogia mundial com experiências educativas diferentes daquela em vigor na escola tradicional.

A característica comum e dominante da "escola nova" teve difusão predominantemente na Europa ocidental e nos Estados Unidos, pois deve ser identificada nos recursos a atitude da criança. A criança é espontaneamente ativa e necessita, portanto, ser libertada dos vínculos da educação familiar, e a educação escolar deve lhe permitir uma livre manifestação de suas inclinações primárias. $\mathrm{Na}$ base da "escola nova" existe, portanto, um ideal comum de educação ou escola ativa.

Experimentos da "escola nova" foram iniciados na Inglaterra por Cecil Reddie (18581932), que abriu em Abbotsholme uma escola para rapazes dos 11 aos 18 anos, a qual ele dirigiu até 1927. Segundo Reddie, o ensino devia ser profundamente mudado para tornar-se mais adequado às exigências da sociedade moderna. Diana Gonçalves Vidal, em 1936, inaugurou uma obra que até 1942 foi responsável pelo levantamento e pela compilação de leis, estatutos e regimentos escolares, memórias, relatórios e pareceres sobre a instrução pública e particular nos vários ramos de ensino no Brasil. (VIDAL; FARIA FILHO, 2005).

Em 1907, na ocasião da morte de Edmond Demolins, Sílvio Romero publicou sua necrologia, evidenciou a desolação do pequeno número de seus adeptos do Rio de Janeiro e aproveitou para fornecer algumas informações do "grande sociólogo" e traçar alguns comentários, a fim de torná-lo mais conhecido do público brasileiro.

A família norte-americana, na concepção de Paul Rousiers, estimula seus filhos a desenvolverem o espírito de iniciativa e o sentimento de responsabilidade, ao contrário dos mestres tradicionais que apelam para o castigo com o objetivo de conseguir a obediência dos discípulos. Os mestres modernos devem estimular o sentimento de obediência, estabelecendo uma relação de confiança e cooperação. Romero revelou que se interessou tanto pela educação formal norte-americana quanto pela informal, aprendida a partir da experiência cotidiana com as "portentosas gentes particulares". (ROUSIERS, 1899).

Neste contexto, uma categoria importante é a da representação, conforme Roger Chartier. Ao criarem representações, os indivíduos descrevem a realidade tal como pensam que ela é ou como gostariam que ela fosse.

Por isso é preciso entender como Sílvio Romero apropriou-se dos impressos pedagógicos. Também são importantes os conceitos do campo intelectual, capital cultural e capital social do sociólogo francês Pierre Bourdieu. Ele compreende a sociedade como um conjunto de campos, microcosmos sociais relativamente autônomos. Entretanto, não vamos neste momento, enveredar por estes elementos. 


\subsection{Representações da Educação Brasileira na República}

Alguns pesquisadores da história da Educação brasileira vêm fazendo uma releitura dos marcos teóricos desde meados dos anos 80 do século XX. Esses marcos teóricos foram estabelecidos pelos escolavonistas brasileiros, pois determinadas leituras só têm efeito na história da educação brasileira a partir dos marcos dos anos 20 e 30 desse mesmo século. Alguns entendimentos receberam recentemente uma boa contribuição crítica da pesquisadora Zaia Brandão, que buscou compreender como se deu essa relação e as representações que foram feitas acerca dela.

Em discurso que proferiu na Academia Brasileira de Letras, em 1906, Sílvio Romero enfatizou características polêmicas da Escola do Recife. Ao longo de sua vida, teve como escopo a análise do ensino público no Brasil. É importante ressaltar que sua experiência docente foi adquirida ao longo de 30 anos como professor do Colégio Pedro II, instituição de ensino, em que ingressou por concurso público em 1882. Romero lutava contra o que dizia ser a mentalidade "reacionária e retrógrada" do ensino brasileiro. Vários de seus trabalhos que tiveram a educação como temática foram publicados na revista já mencionada, "Lucros e Perdas". Nesse período, Sílvio privilegiou os estudos em educação a partir das questões de filosofia e do ensino secundário. Fez crítica ao fato de a escola brasileira ter reduzido o ensino de filosofia a uma só matéria. (BRANDÃO, 1992).

Ele preparou um trabalho intitulado "Notas sobre o ensino público", para o congresso no Rio de Janeiro, em 1883, cuja discussão tomou uma grande dimensão e resultou em sete temas básicos, entre estes: "O Estado Nacional”; "Ensino Público X Ensino Privado"; “A liberdade do ensino"; "A influência estrangeira na educação brasileira"; Ensino primário"; "Ensino secundário e o ensino superior".

Sílvio Romero considera que o Estado nacional tem um caráter e um papel educador; portanto, o ensino deve existir para servi-lo, levando o seu raciocínio a antepor o ensino público ao ensino privado. O ensino público põe-se como uma função racional do Estado preso à questão geral da organização política e das condições sociais como desdobramento das aptidões étnicas e históricas.

Ele propunha que o Estado deveria tornar efetiva e ampla a liberdade completa e radical de ensino, sua doutrina e a utilização do método, o que só seria possível se a união organizasse uma carreira para o magistério que fosse economicamente atrativa, como único 
meio de atrair e manter na docência os mais competentes, dos quais se exigiria uma formação sólida.

Em Sílvio Romero não há como desvincular o debate a respeito dos temas que relacionam Estado nacional e ensino, pois somente a União teria possibilidade de assegurar tais condições para o funcionamento da escola, garantindo aos professores uma carreira atraente.

A discussão de Sílvio Romero a respeito do ensino público no Brasil levava-o a debater a maneira como a influência de outras culturas fazia-se presente entre nós. A mais fundamental de todas as influências que o seu pensamento assumia era, certamente, a prussiana. A escola primária seria, para ele, um instrumento de consolidação do Estado nacional brasileiro, o qual se destinaria a ser o alicerce a formar e unir o caráter do povo, constituindo-se em privilégio da União. Na visão desse intelectual, era a escola primária obrigatória da Prússia aquela que deveria ser tomada no Brasil como modelo para que se pudesse garantir a obrigatoriedade do ensino, havendo necessidade de pessoal docente permanente bem qualificado e bem remunerado.

Silvio Romero fez opção pela cultura alemã que se fortaleceu com o grupo recifense, inclusive Tobias Barreto e começou a abandonar o Positivismo, transformando-se em crítico da doutrina de Augusto Comte. Era indispensável uma aliança da intelectualidade brasileira com a vida intelectual alemã. O germanismo assumido no Brasil não foi um fato isolado, haja vista que o germanismo da escola do Recife teve sempre o caráter intelectual, sem nunca haver assumido conotações de natureza dos interesses políticos da Alemanha no Brasil.

Quando exerceu o mandato de deputado federal, na legislatura de 1900 a 1902, Romero teve oportunidade de, em várias situações, usar a tribuna da câmara para denunciar os procedimentos doutrinários e políticos das colônias alemãs da região sul do Brasil e do descrente modelo de colonização proposto a partir das colônias alemãs. Ele defendia os assentamentos de alemães que deveriam ser feitos com a disseminação das colônias por diferentes regiões do país. Cultivou ao longo de toda a sua vida um grande entusiasmo pela intelectualidade alemã. Ele reafirmou esse entusiasmo que sempre o animou, ressaltando considerar Marx, Lassale, Bakunir, Kropotkin, Lafargue e Bernstein os melhores mestres para o estudo da evolução.

Segundo Carvalho (1997), a influência alemã na cultura brasileira é, portanto, muito antiga e não se inicia apenas no século XIX; ela é visível, no que concerne aos estudos de direito, a exemplo do código civil brasileiro, e a redação do texto final do seu projeto de lei foi assinado em 1917 por Clóvis Bevilacqua. Este condensa toda a discussão do direito 
alemão, assumida pela Escola do Recife a partir da segunda metade do século XIX. Neste sentido e nesse período, o direito brasileiro traz a marca da influência alemã.

Pode-se verificar que os estudos de folclore, especialmente o das áreas ligadas à chamada literatura popular, enfatizam os contos e lendas chamados costumeiramente pelos alemães de "Volkskunde". Uma das melhores expressões foi para o trabalho dos irmãos Jacob e Wilhelm Grimm. O próprio Sílvio Romero, inaugurador dessa tendência no Brasil, recebeu a influência dos autores alemães, a qual está presente nas obras de autores brasileiros que se dedicam ao gênero, a exemplo de Monteiro Lobato e Adelino Brandão. O século XIX no Brasil foi um período em que a pesquisa sobre literatura oral floresceu com muito interesse, principalmente a partir dos estudos feitos por Sílvio Romero.

\section{Considerações Finais}

Com base em leituras da história da educação e da gênese e competências de Sílvio Romero ao longo de sua trajetória, foi possível chegar ao término deste texto a algumas constatações e suscitar reflexões. A partir da educação formal e informal que ele recebeu, esse intelectual sergipano buscou subsídios para elaborar representações da educação brasileira em diferentes correntes teóricas: o evolucionismo de Hebert Spencer e o culturalismo sociológico de Edmond Demolins e Paul Rousiers. Spencer considerava que o papel da educação era preparar o homem para a luta pela vida, formar homens para os desafios da sociedade contemporânea, e priorizava o ensino científico, o único capaz de transmitir conhecimentos úteis.

Demolins defendia a adoção de um currículo ancorado tanto no ensino clássico quanto no científico, pois era preciso habilitar os alunos para exercerem suas profissões. Então, Sílvio apoiou-se tanto em Spencer quanto em Demolins, no tocante à organização do espaço escolar; buscou apoio nas ideias de Demolins, pois tinha o intuito de livrar os discípulos dos vícios da cidade. Deveria também esse espaço ser dividido em casas para professores e diretores. Para definir o currículo e o método, recorreu a Spencer e aos sociólogos da escola de ciências sociais da época.

No tocante à influência alemã na cultura brasileira, observa-se a contribuição dos evolucionistas daquele país. Tobias Barreto, conterrâneo e amigo de Sílvio Romero e um dos fundadores da Escola do Recife, sistematizou todo um quadro de cientificismo, buscando 
consolidar no Brasil um pensamento científico, pois o evolucionismo que aqui chegou através da intelectualidade alemã foi disseminado entre os intelectuais da Escola do Recife. Os estudos de literatura e de folclore no Brasil têm a marca da influência alemã. Sílvio Romero e Monteiro Lobato não escondem a influência recebida pelos irmãos Jacob e Wilhelm Grimm. Romero identifica vários pontos de identidade entre narrativas que recolheu na região Nordeste do Brasil ao longo do século XIX.

Através das leituras feitas por alguns estudiosos, a exemplo de William James, citado por Nascimento (2007), é possível compreender bastante o processo em que se preparava um dos mais importantes dentre os vários pontos de inflexão realizados pela Educação Brasileira: a incorporação do discurso que toma a biologia, a psicologia e, mais tarde, a sociologia como fundamentos científicos da educação, depois das influências da escola nova, das reformas do ensino e, particularmente, da instrução pública.

Por fim, estudar a formação e as competências adquiridas por Sílvio Romero, especificamente na Vila de Lagarto, onde estudou as primeiras letras e aprendeu as orações ensinadas pela mucama Antônia, é gratificante e demorado. As histórias contadas levam o leitor a ingressar em um passado fantástico, principalmente na capital do Império, onde estudou e prestou exames preparatórios no ginásio fluminense. Já em Recife cursou a Faculdade de Direito, e novamente no Rio de Janeiro, cidade onde viveu e trabalhou durante boa parte da sua vida e onde também teve oportunidade de frequentar as livrarias e bibliotecas, chegou a falecer, aos 63 anos.

Eis aqui um pouco do vasto pensamento e teorias do ilustre Silvio Romero, ainda desconhecido pelos próprios sergipanos e que servirão para posteriores análises, reflexões e aprofundamento.

\section{REFERÊNCIAS}

ACADEMIA BRASILEIRA DE LETRAS (ABL). Discurso de recepção ao acadêmico Osório Duque-Estrada, ABL, $1916 . \quad$ Disponível em: <http://www.academia.org.br/antigo/cgi/cgilua.exe/sys/start.htm?infoid=8422\&sid=94>. Acesso em: 12 ago. 2014.

ARAÚJO, Jorge de Souza. Perfil do leitor colonial. Ilhéus: Editora da UESC, 1999.

ARAÚJO, J. A. M. Debates, pompa e majestade: a história de um concurso docente nos trópicos no século XIX. São Cristóvão, 2004. Dissertação (Mestrado em Educação), Programa de Pós-Graduação em Educação, Universidade Federal de Sergipe, 2004. 
BRANDÃO. Zaia. A intelligentsia educacional: um percurso com Paschoal Lemme por entre as memórias e as histórias da escola nova no Brasil. Bragança Paulista, SP: Ed. da Universidade de São Francisco, 1992.

CHARTIER, Roger. À beira da falésia: a história entre incertezas e inquietude. Porto Alegre, RS: Editora da UFRGS, 2002.

DEMOLINS, Edmond. A quoi la superiorité des anglo-saxons? Paris: Librairie de Paris Firmin-Didot et Cie., [s.d].

FERRO, M. do A. B. Literatura escolar e história da educação: cotidiano ideário e práticas pedagógicas. São Paulo, 2000. Tese (Doutoramento em Educação), Faculdade de Educação, Universidade de São Paulo, 2000.

GINZBURG, Carlo. Mitos, emblemas e sinais: morfologia e história. São Paulo, SP: Companhia das Letras, 1989.

HALLEWELL, Laurence. O livro no Brasil. São Paulo, SP: T. A. Queiroz/ Editora da Universidade de São Paulo, 1985.

NASCIMENTO, J. C. A cultura ocultada ou a influência alemã na cultura brasileira durante a segunda metade do século XIX. São Paulo, 1997. Tese de (Doutoramento em História e Filosofia da Educação). Pontifícia Universidade Católica de São Paulo, 1997.

Intelectuais da educação: Sílvio Romero, José Calasans e outros professores. Maceió, AL: EDUFAL, 2007.

PAIM, Antônio. A filosofia da escola de Recife. Rio de Janeiro, RJ: Editora Saga, 1996.

POMPEIA, Raul. O Atheneu. 2. ed., Rio de Janeiro, RJ: Instituto Nacional do Livro, 1971.

ROMERO, Sílvio. Estudos sobre a poesia popular do Brasil. 2. ed. Petrópolis, RJ: Vozes, 1977.

Outros estudos de literatura contemporânea. Lisboa: Typogràphia da Editora, 1906.

ROMERO, Abelardo. Sílvio Romero em família. Rio de Janeiro: Saga, 1960.

ROUSIERS, Paul. L'avie americaine: l'éducation et la société. Paris: Firmin-Didot et Cie., 1899. SCHMIDT, M. L. S. Estilos narrativos e pertença social: análise de histórias de vida. Revista de Psicologia, v. 13, n. 2; v. 14 n. 1/2, dez./jan. 1995/96.

VIDAL, D. G; FARIA FILHO, L. M. de. As lentes da história: estudos de história e historiografia da educação no Brasil. Campinas, SP: Autores Associados, 2005.

SPENCER, Hebert. De l'éducation intellectuelle, morale et physique. 9. ed. Paris: Félix Alcan, 1894. 
SOUZA, C. V. As leituras pedagógicas de Sílvio Romero. 2006. Dissertação (Mestrado em Educação) - Programa de Pós-Graduação em Educação, Universidade Federal de Sergipe, 2006. 